\title{
The Heat Shock Connection of Metabolic Stress and Dietary Restriction
}

\author{
Balázs Dancsó, Zoltán Spiró, Mehmet Alper Arslan, Minh Tú Nguyen, Diána Papp, Péter Csermely, \\ and Csaba Söti*
}

Department of Medical Chemistry, Semmelweis University, Budapest, Hungary

\begin{abstract}
Molecular chaperones and the heat shock response guard and modulate protein conformation, protect proteins from misfolding and aggregation, and maintain signalling and organellar networks. Overnutrition and the metabolic syndrome represent a pro-aging condition, and dietary restriction is the most robust environmental intervention that induces longevity from yeast to mammals. In recent years a considerable effort has been made to elucidate the signaling pathways involved in metabolic signaling. Here we review the current understanding on the connection between metabolic stress, dietary restriction and the heat shock response and highlight results showing chaperone induction as a promising therapeutic strategy to promote healthy aging and to prevent metabolic disorders.
\end{abstract}

Keywords: Aging, caloric restriction, diabetes, heat shock response, resveratrol, sirtuin.

\section{INTRODUCTION: STRESS, AGING AND THE HEAT SHOCK RESPONSE}

Stress can be defined as an environmental change that induces damage at all the molecular, cellular and organismal level, respectively [1,2]. In the organisms several adaptive (stress) responses have evolved to promote survival via the acquisition of stress tolerance. If these responses can not eliminate damage, it results in a functional decline, a socalled distress, while hormesis is the induction of benefical effects by exposure to low doses of chemical or physical agents that are harmful at higher doses $[3,4]$. As aging can be considered as a chronic stress state [5], robust adaptive mechanisms are needed not only for instant survival but also to attain longevity.

An important target of stress at the cellular level is the proteome: during proteotoxic stress and in aging the dysbalance of protein homeostasis and the loss of both protein stability and function occur [6]; besides, protein conformational disorders such as Parkinson's, Alzheimer's, and Huntington's disease, respectively, may mimic the degenerative distress state of aging [7]. The maintenance of proteome integrity is regulated by a network of genes that link stress responses and lifespan. A key player in this regard is the chaperone network [7-10] which is responsibe to maintain and modulate protein conformation, to protect proteins from misfolding and aggregation, to promote translocation and assembly and disassembly of macromolecular complexes [11-14]. The induction of heat shock response is mediated by the heat shock transcription factor 1 (HSF1) [15]. Under normal conditions HSF1 is kept in an inactive, monomeric form by an inhibitory complex of Hsp-s. Upon proteotoxic insults, like heat shock, heavy metals and proteasome inhibitors, Hsp-s interact with denaturated and partially unfolded

*Address correspondence to this author at the Department of Medical Chemistry, Semmelweis University, Budapest, Hungary; Tel: +361-4591500 Extn: 60129; Fax: +361-459-1500 Extn: 60147;

E-mail: csaba.soti@eok.sote.hu proteins, thus HSF1 is titrated out of the inhibitory complex. HSF1 trimerizes, becomes phosphorylated and is translocated into the nucleus, where it binds to consensus sequences of the promoter of heat shock genes (heat shock elements, HSEs). Recent evidence suggests that beyond this feedback loop translational elongation factor eEF1A and a thermometer non-coding RNA (HSR1) together participate in HSF1 activation $[16,17]$. According to this model, the heat shock derived translational shutdown and cytoskeletal collapse make eEF1A capable to bind the concomitantly formed HSR1. Thus the eEF1A-HSR1 complex is able to capture HSF1 released from the aforementioned chaperone complex and promotes trimerization and further activation steps, linking general translation and RNA metabolism to the heat shock response. After activation and nuclear translocation HSF1 is located within $30 \mathrm{~s}$ in so-called stress granules [1820]. These discrete subnuclear granules contain a plethora of proteins with unknown functions, including splicing factors suggesting a special micro-compartment for fine-tuning transcriptional responses during stress [18,21,22].

Mapping out the connection between the heat shock response and longevity has already begun with ambiguous results. The nematodal HSF1 ortholog HSF-1 overexpression induces longevity, while HSF-1 knock out shortens life-span in C. elegans [23,24], while mice lacking HSF1 do not display shorter lifespan [25]. Furthermore, studies in worms expressing GFP under the hsp 16.2 promoter demonstrated that the robustness of the heat shock response may predict lifespan [26]. However, a recent study using hsp22 and hsp70 reporter Drosophila strains reported a negative correlation between reporter expression and lifespan warranting further research in this direction [27].

\section{OBESITY AND DIABETES AS A METABOLIC DISTRESS: THE PROTECTIVE ROLE OF MOLE- CULAR CHAPERONES}

Overnutrition is one of the leading medical problems in the developed world. It is a result of an imbalanced diet, 
where the energy consumption is higher than the energy expenditure, and it leads to the development of the metabolic syndrome, characterized by obesity, type 2 diabetes, insulin resistance, dyslipidaemia and hypertension $[28,29]$. Metabolic syndrome is also a risk factor of atherosclerosis, stroke, cancer, arthritis and diabetes. Thus, the metabolic syndrome and diabetes may be perceived as a chronic metabolic distress which induces diseases and limits life expectancy.

Metabolic disturbances in diabetes induce a number of alterations in protein homeostasis. Glycation of the small chaperone $\alpha$-crystallin of the lens compromises its chaperone activity and contributes to cataract formation [30]. High glucose-induced oxidative stress in the obese Zucker rat led to protein misfolding and aggregate formation could be cleared by autophagy, but not by the proteasome [31]. Elevated levels of HSF1, Hsp70 and Hsp90 that were found in the pancreas of diabetic monkeys may compensate for the altered protein homeostasis [32]. Intriguingly, decreased level of Hsp70 was found in the muscle of diabetic patients, as well as in the blood and in the liver of diabetic monkeys, where the level of HSF1 and Hsp70 and Hsp90 declined significantly [32,33] Indeed, impaired insulin signaling reduces HSF1 transactivation via the activation of glycogen synthase kinase-3 (GSK-3) and extra-cellular regulated kinase-1 (ERK-1) and c-jun N-terminal kinase (JNK) [34,35]. Decreased Hsp70 may not be able to inhibit JNK-induced inflammatory signaling, giving rise to a vicious cycle $[35,36]$. High glucose alters the interaction of the specific chaperone Hsp90 with two prominent clients endothelial nitric oxide synthase (eNOS) and inhibitor of kappaB kinase (IKK) providing a mechanistic basis for endothelial dysfunction $[37,38]$. How altered chaperone levels and function may contribute in other ways to peripheral insulin resistance, inflammation and to an altered extracellular stress signaling remains to be seen.

There are a number of experiments demonstrating the connection between diabetes and the heat shock response. Physical exercise is able to both raise chaperone levels and reverse diabetic alterations [34,35]. Besides, both the antidiabetic drug, metformin and the alkaloid, berberin promote the association of eNOS with Hsp90 and augment NO production and preserve endothelial function [39,40]. More importantly, a $41^{\circ} \mathrm{C}$ heat treatment once a week for 12 weeks improved glucose tolerance and reduced stress-activated signaling in rats fed by a high-fat diet suggesting a crosstalk between the development of HSF1 dependent thermotolerance and metabolic stress tolerance [41]. The chaperone coinducer bimoclomol derivative, BRX-220 was also able to improve insulin sensitivity of both Zucker fatty diabetic rats, and streptozotocin-treated diabetic rats [42]. Finally, a recent study demonstrated that besides heat shock either overexpression or pharmacologic induction of Hsp70 by a novel chaperone co-inducer BGP-15 was sufficient to prevent the development of obesity-induced insulin resistance in fat-fed mice [43]. Strikingly, a 1-month treatment with BGP-15 significantly improved insulin sensitivity in insulin-resistant, nondiabetic human patients [44]. These protective effects may be related to an improved protein homeostasis, a more efficient modulation of signaling networks and to a better connectivity of subcellular organellar networks, such as the ER and the cytosol $[8,45]$. All these experiments highlight a vast therapeutic and preventive potential of chaperone induction in metabolic disorders.

\section{DIETARY RESTRICTION IS AN INDUCER OF LONGEVITY AND OF THE HEAT SHOCK RES- PONSE}

Dietary (caloric) restriction, a moderate (30-40\%) reduction of caloric intake with maintained nutrient supply is the most robust intervention that induces longevity from yeast to mammals. Dietary restriction also decreases the incidence of age-related diseases, such as cancer, diabetes, cardiovascular and neurodegenerative diseases by inducing changes in metabolism, protein biogenesis and turnover as well as by evoking resistance to a variety of stresses $[46,47]$. Thus, dietary restriction may emerge as a hormetic metabolic stress that activates various defense mechanisms to promote longevity.

Early studies showed that dietary restriction was able to restore the age-induced loss of Hsp70 transcription via the preservation of HSF1 activation in rat hepatocytes [48,49]. As a functional consequence, dietary restriction highly improved thermotolerance and was able to rescue $100 \%$ vs $50 \%$ of old rats subjected to hyperthermia [50]. These findings have been recapitulated in rat intestine, neural tissue, skeletal muscle and in heart myocardium, suggesting that a more efficient heat shock response induced by dietary restriction may improve muscle and neuronal function, protect from muscle cell loss and importantly may exert cytoprotection against ischemic episodes [51-55]. A small, but significant cytoprotection from heat stress could be transferred with blood serum to HepG2 cells by culturing them in serum obtained from human subjects undergoing caloric restriction, however, this study found no difference in basal Hsp70 levels [56]. Using transcriptional profiling, independent studies demonstrated a better maintenance of stress responses including chaperones both in liver and in muscle, respectively, of caloric restricted primates [57,58]. This effect was reflected in an efficient protection in both nematode and mouse models of misfolding models of neurodegenerative disorders $[59,60]$. Similarly to food restriction, the mimetic 2deoxyglucose was shown to induce chaperones and protect neuronal cells from excitotoxic, oxidative and proteotoxic injury [61,62]. Intriguingly, 2-deoxyglucose blunted the Hsp70 induction and thermotolerance of prostate cancer cells suggesting that an otherwise hormetic intervention may induce a distress in the already stressed tumor cells and providing one plausible mechanism for the potent antitumor effect of dietary restriction and fasting [63]. Since an increased protein turnover is implicated in the 'cleansing' effects of dietary restriction, and chaperones are known to play an important role both in proteasomal degradation and in chaperone-mediated autophagy, it would be worth studying their crosstalk to gain a better understanding on the interplay between these processes [52,55,64-67].

\section{THE HEAT-SHOCK RESPONSE IN THE DIETARY RESTRICTION-RELATED SIGNALING NETWORK}

In recent years evidence has been accumulated that dietary restriction is not only a simple consequence of restriction of fuel and metabolism but initiates a highly regulated and orchestrated process that drives energy allocation from 
reproduction to self maintenance during low food availability. Due to its versatility, short lifespan and ease of genetic manipulations much of the understanding has been obtained in the nematode $C$. elegans. Here we will mainly rely on data from worms and supplement it with findings from higher organisms.

A major endocrine sensor of food supply is insulin signaling. Reduction in insulin signaling extends life span in various organisms $[68,69]$. The essential role of HSF-1 and the chaperone-network in this pathway has been proven in the nematode Caenorhabditis elegans, acting in concert with the forkhead transcription factor FoxO/daf-16 [24,70]. Consequently, insulin-signaling mutations delay the onset of polyglutamine toxicity in worms [71].

To address the mechanism of dietary restriction a number procedures have been developed in $C$. elegans. All of them induce a further life extension of already long-lived insulin signaling mutants suggesting that the effects of dietary restriction involve different mechanism apart form insulin-like signaling. A dilution of the food source bacteria from $10^{11}$ to $10^{8} \mathrm{E}$. coli/ml on solid agar extended lifespan of worms by 20-30\%. Despite an increased stress resistance, the C. elegans HSF1 ortholog $h s f-1$ was dispensable, however, it fully depended on the AMP-dependent protein kinase AMPK/aak2 and on FoxO/daf-16 [72,73]. A similar longevity by the dilution of the bacterial food peptone was also mediated by daf-16, however, the contribution of $h s f-1$ is, as yet, unknown [74]. The reduction of pharynx pumping rate by a genetic mutation (eat-2) depends on the mitochondrial gene clk-1 while daf-16- and $h s f-1$ are indispensable, moreover, the necessity of $c l k-1$ has been shown in the bacterial dilution protocol, too $[24,73,75]$. Yet, bacterial dilution combined with eat-2 mutation produced a synergistic longevity [73]. Separate studies from two labs employed liquid medium, where diluting bacteria extended lifespan which was also largely daf-16-independent, however, depended on neuroendocrine signals by either the transcription factors FoxA/pha-4 or Nrf2/skn-1, respectively [76,77]. Notably, pha-4 also seemed to mediate the longevity of eat-2 mutants
[76]. The involvement of the heat shock response in these models has not been addressed. Dietary restriction in Drosophila appeared to be FoxO-independent [78]. The results highlighted above argue that a partial reduction of food source in invertebrates is heterogeneous intervention targeting various nodes of a highly connected signaling network and draws attention to the careful design and interpretation of research in mammalian models.

After reaching the adult stage, $C$. elegans displays a robust $50 \%$ increase in lifespan either in axenic medium almost devoid of calories or even in the total absence of the food source E. coli [79-81]. The life extending mechanism of these interventions is totally different from a partial food reduction, since $(i)$ serial dilution of bacteria on the plates below a threshold (cca. $10^{7} \mathrm{E}$. coli/ml) killed worms within two days [73], (ii) the longevity by bacterial deprivation was independent on FoxO/daf-16 and AMPK/aak-2 [80], (iii) the presence of metabolically active live bacteria, or their product prevented the food deprivation-induced longevity $[79,82]$. Indeed, both the longevity induced as well as a potent protection in several proteotoxic models by bacterial deprivation required $h s f-1$ [60]. It may be hypothesized that beyond the optimum food supply that finely tunes metabolism a signal produced by live microorganism exerts a constitutive inhibition on stress responses and HSF-1. Further research is necessary to reveal the nature and the pathway of the inhibition. For a summary of genes involved in dietary restriction-induced longevity please refer to Table $\mathbf{1}$.

Another important nutrient sensor is the target of rapamycin (TOR) kinase which is activated by both nutrient supply and insulin. Inhibition of TOR in wild type and in eat-2 mutant worms induces longevity by activating translation and inhibiting autophagy [66,83]. Reduction of translational output per se induces thermotolerance and longevity, the latter being additive to that of both insulin-like and eat-2 mutants [83,84]. Similarly, both insulin-like and eat-2 mutants require autophagy for their longevity, however, activation of autophagy is not sufficient to extend lifespan $[66,67]$. Though there is no direct evidence on the role of the protea-

Table 1. Requirement of Genes for Longevity in Various Dietary Restriction (Mimetic) Interventions C. elegans. See the text for details and for references. * B. Dancsó and C. Sőti, unpublished results, ** Tóth ML, Dancsó B, Csermely P and Sőti C, submitted manuscript

\begin{tabular}{|c|c|c|c|c|c|c|c|}
\hline Intervention & \multicolumn{7}{|c|}{ Genes (human ortholog) } \\
\hline Bacterial dilution & yes & yes & no & Yes & no & no & no \\
\hline Peptone dilution & yes & yes & $?$ & $?$ & $?$ & $?$ & $?$ \\
\hline Liquid DR \#1 & no & $?$ & $?$ & $?$ & yes & $?$ & $?$ \\
\hline Liquid DR \#2 & partial & partial & $?$ & $?$ & $?$ & yes & $?$ \\
\hline Bacterial deprivation & no & $*$ no & yes & $?$ & $?$ & $?$ & $*$ no \\
\hline Resveratrol & yes/no & yes & $* *$ yes & $?$ & $?$ & $?$ & yes \\
\hline
\end{tabular}


somal system in dietary restriction, a close relationship can be suspected. A proper protein homeostasis seems to be a critical determinant in longevity and closely connected to the mechanism of dietary restriction. Namely, translation modulates protein output, molecular chaperones guard protein conformation and protein disposal clears the damaged and unnecessary proteins and provides fuel from intrinsic stores to build new proteins, elements of an adaptive response.

HSF1 and chaperones are involved in several physiological and housekeeping processes like signaling and immunity, however, the exact contribution of their significance related or unrelated to protein homeostasis has not been addressed. Taking use of the poikilothermic nature of C. elegans we investigated the effect of dietary deprivation on the lifespan of wild type and $h s f-1$ loss-of function animals at temperatures below and above the ambient $20^{\circ} \mathrm{C}$. Fig. (1) shows that decreasing temperature progressively lengthens the lifespan of both the wild type and $h s f-1$ worms to a similar extent (to $280 \%$ mean lifespan at $15^{\circ} \mathrm{C}$ ) suggesting that at the temperatures tested there is a uniform need of $h s f-1$ for survival. Besides, dietary deprivation progressively extends the lifespan of wild type worms with increasing temperature. However, this effect is completely abolished in $h s f-1$ mutants. These data indicate that either the effect of dietary deprivation is independent of the protein homeostatic burden or HSF-1 mediates the longevity effect via both protein-maintenance and independent means. Indeed, it has been shown that HSF1 regulates $3 \%$ of the genome in yeast and supports such core cellular functions as cell size, translation and ribosome biogenesis as well as glucose metabolism in mammalian tumor cell lines $[85,86]$. It may well be, that HSF1 orchestrates a network that optimizes fuel utilization and overall cellular and organismal functions in the postmitotic worm to attain efficient self maintenance and longevity. However, the mechanisms and the gene network involved remains to be identified.

\section{RESVERATROL AND SIR2 ARE ACTIVATORS OF HSF1}

The plant polyphenol resveratrol recapitulates the dietary restriction-induced longevity of yeast, invertebrates and mice on a high-fat diet (but not on a normal diet) [87-91]. Other studies, nevertheless, could not show an increased longevity upon resveratrol treatment in invertebrate and normal fed mouse trials $[92,93]$. Resveratrol has been shown to act via the Sir2 (silent information regulator) sirtuin family of $\mathrm{NAD}^{+}$-dependent protein deacetylases in a FoxO/daf-16independent manner [88,94]. Sir2 deacetylates a number of key regulatory proteins including FoxO, PPAR $\gamma$, and its activator PGC-1 $\alpha$ and, responsible for survival under stress and the metabolic change [95-97]. Genetic activation of Sir2/sir2.1 induces a lifespan extension in worms and mice overexpressing the major mammalian ortholog SirT1 show reduced energy expenditure, improved metabolism and protection from diabetes [98-100]. Sir2/sir-2.1 seems to mediate some forms of dietary restriction including the eat-2 mutation in $C$. elegans and SirT1 is required for dietary restriction-induced physical activity in mice [101-103]. However, in other studies dietary restriction by eat-2 by bacterial dilution or by bacterial deprivation did not depend on Sir2 [73,80,83].
A)

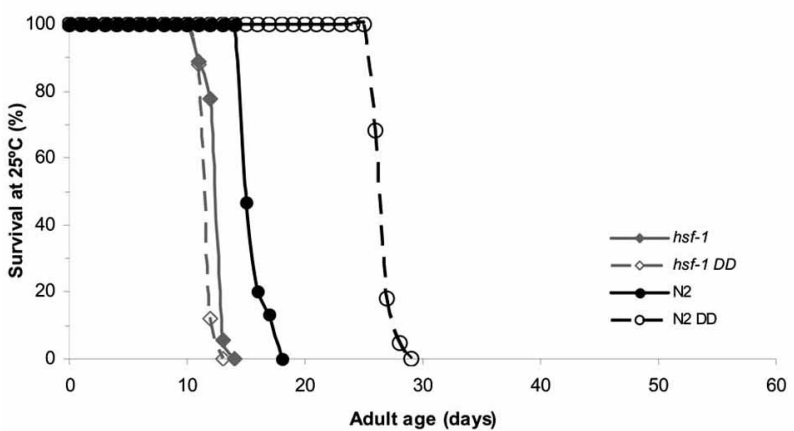

B)

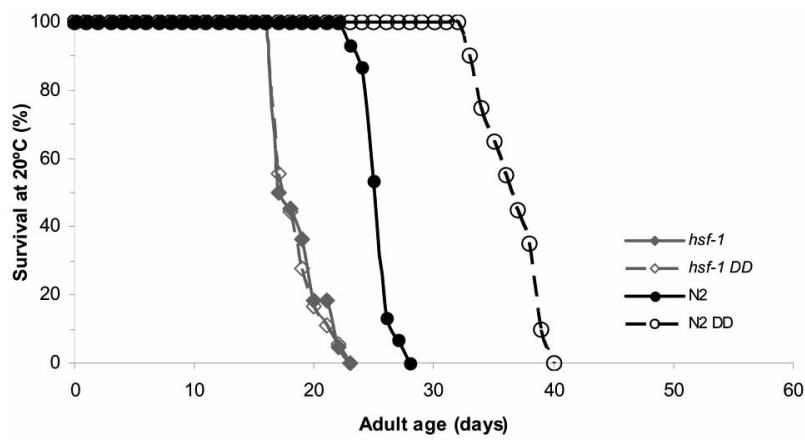

C)

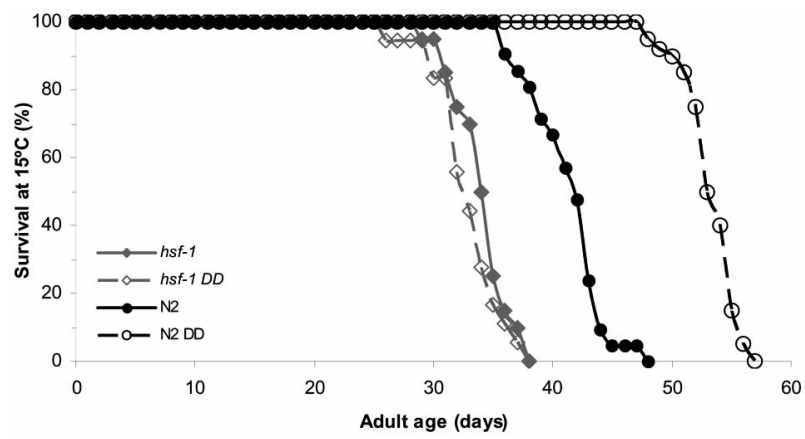

Fig. (1). HSF-1 mediates dietary deprivation-induced life-span extension at various temperatures. Survival curves of wild type (N2) and $h s f-1(s y 441)$ loss of function nematodes at $25^{\circ} \mathrm{C}(\mathbf{A}), 20^{\circ} \mathrm{C}$ (B) or $15^{\circ} \mathrm{C}(\mathbf{C})$ in the presence (closed symbols) or absence (dietary deprivation, DD, open symbols) of the food source, E. coli. Synchronized strains were grown on NGM plates containing $50 \mu \mathrm{M}$ FudR (5-fluoro-2'-deoxyuridine). DD was initiated at day 4 of adulthood. Animals that crawled off the plate, exploded, bagged, or became contaminated were removed from the evaluation process. The figure shows representative curves of 3 independent experiments.

Both resveratrol and Sir2/SirT1 were protective in misfolding neurodegenerative models suggesting an improved protein homeostasis [104,105]. As a potential mechanism, we have shown that resveratrol specifically induces the heat shock response and protects various mammalian cells against heat stress and proposed a Sir2-dependent modulation of HSF1 [106]. Recently this has been experimentally demonstrated by showing that SirT1 deacetylates HSF1 and prolongs its binding to the heat shock promoter [107]. However, the exact contribution of the heat-shock response to resvera- 
trol-induced longevity remained unknown. Recent results from our lab show that HSF-1 mediates resveratrol-induced longevity in a manner dependent on Sir-2.1 in C. elegans (Tóth ML, Dancsó B, Csermely $\mathrm{P}$ and Söti C, submitted manuscript, Table 1). These findings link the metabolic and proteotoxic stress responses in longevity regulation in invertebrates. How this interaction modulates aging in mammals remains to be determined.

\section{SUMMARY AND PERSPECTIVES}

The observations presented in this review demonstrate an intimate connection between metabolic disturbances, dietary restriction and protein homeostasis with a special emphasis on the HSF1-orchestrated heat shock response. Most experiments elucidating the dietary restriction-induced longevity regulation have been performed in invertebrates and analyzing one or two components of the signaling pathways. Future studies employing systems biology and mammalian models will reveal the topology of the signaling network and the place of HSF1 in response of dietary restriction. This may lead to the development of novel strategies to attain the final goal of healthy aging and to prevent or heal civilization diseases.

\section{ACKNOWLEDGEMENTS}

Work in the authors' laboratory was supported by a research grant from the EU (FP6-518230, PROTEOMAGE; FP7-200970, WhyWeAge), from the Hungarian Science Foundation (OTKA K69105) and from a joint grant of the Hungarian Science Foundation and Norway Grants (NNF78794). C.S. is a Bolyai Research Scholar of the Hungarian Academy of Sciences. The authors have declared that no competing interests exist.

\section{REFERENCES}

[1] Sőti, C.; Csermely, P. Protein stress and stress proteins: implications in aging and disease. J. Biosci., 2007, 328(3), 511-515.

[2] Szalay, M.S.; Kovács, I.A.; Korcsmáros, T.; Böde, C.; Csermely, P. Stress-induced rearrangements of cellular networks: Consequences for protection and drug design FEBS Lett., 2007, 581(19), 36753680 .

[3] Cypser, J.R.; Johnson, T.E. Multiple stressors in Caenorhabditis elegans induce stress hormesis and extended longevity. Gerontol. A Biol. Sci. Med. Sci., 2002, 57(3), B109-114.

[4] Calabrese, E.J. The failure of dose-response models to predict low dose effects: a major challenge for biomedical, toxicological and aging research. Biogerontology, 2006, 7(2), 119-122.

[5] Epel, E.S. Psychological and metabolic stress: a recipe for accelerated cellular aging? Hormones, 2009, 8(1), 7-22.

[6] Morimoto, R.I.; Cuervo, A.M. Protein homeostasis and aging: taking care of proteins from the cradle to the grave. J. Gerontol. A Biol. Sci. Med. Sci., 2009, 63A(2), 167-170.

[7] Morimoto, R.I. Proteotoxic stress and inducible chaperone networks in neurodegenerative disease and aging. Genes Dev., 2008, 22(11), 1427-1438.

[8] Söti, C.; Pal, C.; Papp, B.; Csermely, P. Molecular chaperones as regulatory elements of cellular networks. Curr. Opin. Cell Biol., 2005, 17(2), 210-215.

[9] Söti, C.; Csermely, P. Aging cellular networks: chaperones as major participants. Exp. Gerontol., 2007, 42(1-2), 113-119.

[10] Palotai, R.; Szalay, M.S.; Csermely, P. Chaperones as integrators of cellular networks: changes of cellular integrity in stress and diseases. IUBMB Life, 2008, 60(1), 10-18.

[11] Hartl, F.U.; Hayer-Hartl, M. Molecular chaperones in the cytosol: from nascent chain to folded protein. Science, 2002, 295(5561), 1852-1858.
[12] Deuerling, E.; Bukau, B. Chaperone-assisted folding of newly synthesized proteins in the cytosol. Crit. Rev. Biochem. Mol. Biol., 2004, 39(5-6), 261-277.

[13] Bukau, B.; Weissman, J.; Horwich, A. Molecular chaperones and protein quality control. Cell, 2006, 125(3), 443-451.

[14] Ron, D.; Walter, P. Signal integration in the endoplasmic reticulum unfolded protein response. Nat. Rev. Mol. Cell Biol., 2007, 8(7), 519-529.

[15] Morimoto, R.I. Regulation of the heat shock transcriptional response: cross talk between a family of heat shock factors, molecular chaperones, and negative regulators. Genes. Dev., 1998, 12(24), 3788-3796.

[16] Shamovsky, I.; Ivannikov, M.; Kandel, E.S.; Gershon, D.; Nudler, E. RNA-mediated response to heat shock in mammalian cells. $\mathrm{Na}$ ture, 2006, 440(7083), 556-560.

[17] Shamovsky, I.; Nudler, E. New insights into the mechanism of heat shock response activation. Cell. Mol. Life Sci., 2008, 65(6), 855861.

[18] Pirkkala, L.; Nykänen, P.; Sistonen, L. Roles of the heat shock transcription factors in regulation of the heat shock response and beyond. FASEB J., 2001, 15(7), 1118-1131.

[19] Sarge, K.D.; Murphy, S.P.; Morimoto, R.I. Activation of heat shock gene transcription by heat shock factor 1 involves oligomerization, acquisition of DNA-binding activity, and nuclear localization and can occur in the absence of stress. Mol. Cell. Biol., 1993, 13(3), 1392-1407.

[20] Jolly, C.; Usson, Y.; Morimoto, R.I. Rapid and reversible relocalization of heat shock factor 1 within seconds to nuclear stress granules. Proc. Natl. Acad. Sci. USA, 1999, 96(12), 6769-6774.

[21] Weighardt, F.; Cobianchi, F.; Cartegni, L.; Chiodi, I.; Villa, A.; Riva, S.; Biamonti, G. A novel hnRNP protein (HAP/SAF-B) enters a subset of hnRNP complexes and relocates in nuclear granules in response to heat shock. J. Cell. Sci., 1999, 112 (Pt 10), 14651476.

[22] Denegri, M.; Chiodi, I.; Corioni, M.; Cobianchi, F.; Riva, S.; Biamonti, G. Stress-induced nuclear bodies are sites of accumulation of pre-mRNA processing factors. Mol. Biol. Cell., 2001, 12(11), 3502-3514.

[23] Garigan, D.; Hsu, A.L.; Fraser, A.G.; Kamath, R.S.; Ahringer, J.; Kenyon, C. Genetic analysis of tissue aging in Caenorhabditis elegans: a role for heat-shock factor and bacterial proliferation. Genetics, 2002, 161(3), 1101-1112.

[24] Hsu, A.L.; Murphy, C.T.; Kenyon, C. Regulation of aging and agerelated disease by DAF-16 and heat-shock factor. Science, 2003, 300(5622), 1142-1145.

[25] Xiao, X.; Zuo, X.; Davis, A.A.; McMillan, D.R.; Curry, B.B.; Richardson, J.A.; Benjamin, I.J. HSF1 is required for extraembryonic development, postnatal growth and protection during inflammatory responses in mice. EMBO J., 1999, 18(21), 5943-5952.

[26] Rea, S.L.; Wu, D.; Cypser, J.R.; Vaupel, J.W.; Johnson, T.E. A stress-sensitive reporter predicts longevity in isogenic populations of Caenorhabditis elegans. Nat. Genet., 2005, 37(8), 894-898.

[27] Yang, J.; Tower, J. Expression of hsp22 and hsp70 transgenes is partially predictive of drosophila survival under normal and stress conditions. J. Gerontol. A Biol. Sci. Med. Sci., 2009, 64(8), 828838 .

[28] Alberti, K.G.; Zimmet, P.; Shaw, J. The metabolic syndrome- a new worldwide definition. Lancet, 2005, 366(9491), 1059-1062.

[29] Kahn, S.E.; Hull, R.L.; Utzschneider, K.M. Mechanisms linking obesity to insulin resistance and type 2 diabetes. Nature, 2006, 444(7121), 840-846.

[30] Kumar, P.A.; Kumar, M.S.; Reddy, G.B. Effect of glycation on alpha-crystallin structure and chaperone-like function. Biochem. J., 2007, 408(2), 251-258.

[31] Kaniuk, N.A.; Kiraly, M.; Bates, H.; Vranic, M.; Volchuk, A.; Brumell, J.H. Ubiquitinated-protein aggregates form in pancreatic beta-cells during diabetes-induced oxidative stress and are regulated by autophagy. Diabetes, 2007, 56(4), 930-939.

[32] Kavanagh, K.; Zhang, L.; Wagner, J.D. Tissue-specific regulation and expression of heat shock proteins in type 2 diabetic monkeys. Cell Stress Chaperones, 2009, 14(3), 291-299.

[33] Kurucz, I.; Morva, A.; Vaag, A.; Eriksson, K.F.; Huang, X.; Groop, L.; Koranyi, L. Decreased expression of heat shock protein 72 in skeletal muscle of patients with type 2 diabetes correlates with insulin resistance. Diabetes, 2002, 51(4), 1102-1109. 
[34] Atalay, M.; Oksala, N.; Lappalainen, J.; Laaksonen, D.E.; Sen, C.K.; Roy, S. Heat shock proteins in diabetes and wound healing. Curr. Protein. Pept. Sci., 2009, 10(1), 85-95.

[35] Hooper, P.L.; Hooper, P.L. Inflammation, heat shock proteins, and type 2 diabetes. Cell Stress Chaperones, 2009, 14(2), 113-115.

[36] Gabai, V.L.; Sherman, M.Y. Invited review: Interplay between molecular chaperones and signaling pathways in survival of heat shock. J. Appl. Physiol., 2002, 92(4), 1743-1748.

[37] Mohan, S.; Konopinski, R.; Yan, B.; Centonze, V.E.; Natarajan, M. High glucose-induced IKK-Hsp-90 interaction contributes to endothelial dysfunction. Am. J. Physiol. Cell Physiol., 2009, 296(1), C182-192.

[38] Lei, H.; Venkatakrishnan, A.; Yu, S.; Kazlauskas, A. Protein kinase A-dependent translocation of Hsp90 alpha impairs endothelial nitric-oxide synthase activity in high glucose and diabetes. J. Biol. Chem., 2007, 282(13), 9364-9371.

[39] Davis, B.J.; Xie, Z.; Viollet, B.; Zou, M.H. Activation of the AMPactivated kinase by antidiabetes drug metformin stimulates nitric oxide synthesis in vivo by promoting the association of heat shock protein 90 and endothelial nitric oxide synthase. Diabetes, 2006, $55(2), 496-505$.

[40] Wang, Y.; Huang, Y.; Lam, K.S.; Li, Y.; Wong, W.T.; Ye, H.; Lau, C.W.; Vanhoutte, P.M.; Xu, A. Berberine prevents hyperglycemiainduced endothelial injury and enhances vasodilatation via adenosine monophosphate-activated protein kinase and endothelial nitric oxide synthase. Cardiovasc. Res., 2009, 82(3), 484-492.

[41] Gupte, A.A.; Bomhoff, G.L.; Swerdlow, R.H.; Geiger, P.C. Heat treatment improves glucose tolerance and prevents skeletal muscle insulin resistance in rats fed a high-fat diet. Diabetes, 2009, 58(3), 567-578.

[42] Kurthy, M.; Mogyorosi, T.; Nagy, K.; Kukorelli, T.; Jednakovits, A.; Talosi, L.; Biro, K. Effect of BRX-220 against peripheral neuropathy and insulin resistance in diabetic rat models. Ann. $N Y$. Acad. Sci., 2002, 967, 482-489.

[43] Chung, J.; Nguyen, A.K.; Henstridge, D.C.; Holmes, A.G.; Chan, M.H.; Mesa, J.L.; Lancaster, G.I.; Southgate, R.J.; Bruce, C.R.; Duffy, S.J.; Horvath, I.; Mestril, R.; Watt, M.J.; Hooper, P.L.; Kingwell, B.A.; Vigh, L.; Hevener, A.; Febbraio, M.A. HSP72 protects against obesity-induced insulin resistance. Proc. Natl. Acad. Sci. USA, 2008, 105(5), 1739-1744.

[44] Literáti-Nagy, B.; Kulcsár, E.; Literáti-Nagy, Z.; Buday, B.; Péterfai, E.; Horváth, T.; Tory, K.; Kolonics, A.; Fleming, A.; Mandl, J.; Korányi, L. Improvement of insulin sensitivity by a novel drug, BGP-15, in insulin-resistant patients: a proof of concept randomized double-blind clinical trial. Horm. Metab. Res., 2009, 41(5), 374-380.

[45] McClellan, A.J.; Xia, Y.; Deutschbauer, A.M.; Davis, R.W.; Gerstein, M.; Frydman, J. Diverse cellular functions of the Hsp90 molecular chaperone uncovered using systems approaches. Cell, 2007, 131(1), 121-135.

[46] Weindruch, R.; Sohal, R.S. Seminars in medicine of the Beth Israel Deaconess Medical Center. Caloric intake and aging. N. Engl. J. Med., 1997, 337(14), 986-994.

[47] Masoro, E.J. Overview of caloric restriction and ageing. Mech. Ageing Dev., 2005, 126(9), 913-922.

[48] Heydari, A.R.; Wu, B.; Takahashi, R.; Strong, R.; Richardson, A. Expression of heat shock protein 70 is altered by age and diet at the level of transcription. Mol. Cell. Biol., 1993, 13(5), 2909-1918.

[49] Heydari, A.R.; You, S.; Takahashi, R.; Gutsmann, A.; Sarge, K.D.; Richardson, A. Effect of caloric restriction on the expression of heat shock protein 70 and the activation of heat shock transcription factor 1. Dev. Genet., 1996, 18(2), 114-124.

[50] Hall, D.M.; Oberley, T.D.; Moseley, P.M.; Buettner, G.R.; Oberley, L.W.; Weindruch, R.; Kregel, K.C. Caloric restriction improves thermotolerance and reduces hyperthermia-induced cellular damage in old rats. FASEB J., 2000, 14(1),78-86.

[51] Ehrenfried, J.A.; Evers, B.M.; Chu, K.U.; Townsend, C.M.Jr.; Thompson, J.C. Caloric restriction increases the expression of heat shock protein in the gut. Ann. Surg., 1996, 223(5), 592-599.

[52] Selsby, J.T.; Judge, A.R.; Yimlamai, T.; Leeuwenburgh, C.; Dodd S.L. Life long calorie restriction increases heat shock proteins and proteasome activity in soleus muscles of Fisher 344 rats. Exp. Gerontol., 2005, 40(1-2), 37-42.

[53] Frier, B.; Locke, M. Preservation of heat stress induced myocardial hsp 72 in aged animals following caloric restriction. Exp. Gerontol., 2005, 40(7), 615-617.
[54] Colotti, C.; Cavallini, G.; Vitale, R.L.; Donati, A.; Maltinti, M.; Del Ry, S.; Bergamini, E.; Giannessi, D. Effects of aging and antiaging caloric restrictions on carbonyl and heat shock protein levels and expression. Biogerontology, 2005, 6(6), 397-406.

[55] Rangaraju, S.; Hankins, D.; Madorsky, I.; Madorsky, E.; Lee, W.H.; Carter, C.S.; Leeuwenburgh, C.; Notterpek, L. Molecular architecture of myelinated peripheral nerves is supported by calorie restriction with aging. Aging Cell, 2009, 8(2), 178-191.

[56] Allard, J.S.; Heilbronn, L.K.; Smith, C.; Hunt, N.D.; Ingram, D.K.; Ravussin, E.; Pennington CALERIE Team; de Cabo, R. In vitro cellular adaptations of indicators of longevity in response to treatment with serum collected from humans on calorie restricted diets. PLoS One, 2008, 3(9), 3211 .

[57] Cao, S.X.; Dhahbi, J.M.; Mote, P.L.; Spindler, S.R. Genomic profiling of short- and long-term caloric restriction effects in the liver of aging mice. Proc. Natl. Acad. Sci. USA, 2001, 98(19), 1063010635

[58] Kayo, T.; Allison, D.B.; Weindruch, R.; Prolla, T.A. Influences of aging and caloric restriction on the transcriptional profile of skeletal muscle from rhesus monkeys. Proc. Natl. Acad. Sci. USA, 2001 98(9), 5093-5098.

[59] Duan, W.; Guo, Z.; Jiang, H.; Ware, M.; Li. X.J.; Mattson, M.P Dietary restriction normalizes glucose metabolism and BDNF levels, slows disease progression, and increases survival in huntingtin mutant mice. Proc. Natl. Acad. Sci. USA, 2003, 100(5), 2911-2916.

[60] Steinkraus, K.A.; Smith, E.D.; Davis, C.; Carr, D.; Pendergrass, W.R.; Sutphin, G.L.; Kennedy, B.K.; Kaeberlein, M. Dietary restriction suppresses proteotoxicity and enhances longevity by an hsf-1-dependent mechanism in Caenorhabditis elegans. Aging Cell, 2008, 7(3), 394-404.

[61] Lee, J.; Bruce-Keller, A.J.; Kruman, Y.; Chan, S.L.; Mattson, M.P. 2-Deoxy-D-glucose protects hippocampal neurons against excitotoxic and oxidative injury: evidence for the involvement of stress proteins. J. Neurosci. Res., 1999, 57(1), 48-61.

[62] Guo, Z.H.; Mattson, M.P. In vivo 2-deoxyglucose administration preserves glucose and glutamate transport and mitochondrial function in cortical synaptic terminals after exposure to amyloid betapeptide and iron: evidence for a stress response. Exp. Neurol., 2000, 166(1), 173-179.

[63] Roigas, J.; Jensen, C.A.; Wallen, E.S.; Loening, S.A.; Wharton, W.; Moseley, P.L. Repression of thermotolerance in Dunning R3327 prostate carcinoma cells by 2-deoxy-glucose. Int. J. Hyperthermia, 2004, 20(6),557-566.

[64] Cuervo, A.M. Calorie restriction and aging: the ultimate "cleansing diet". J. Gerontol. A Biol. Sci. Med. Sci., 2008, 63(6), 547-549.

[65] Donati, A.; Recchia, G.; Cavallini, G.; Bergamini E. Effect of aging and anti-aging caloric restriction on the endocrine regulation of rat liver autophagy. J. Gerontol. A Biol. Sci. Med. Sci., 2008, 63(6), 550-555.

[66] Hansen, M.; Chandra, A.; Mitic, L.L.; Onken, B.; Driscoll, M. Kenyon, C. A role for autophagy in the extension of lifespan by dietary restriction in C. elegans. PLoS Genet., 2008, 4(2), e24.

[67] Tóth, M.L.; Sigmond, T.; Borsos, E.; Barna, J.; Erdélyi, P.; TakácsVellai, K.; Orosz, L.; Kovács, A.L.; Csikós, G.; Sass, M.; Vellai, T. Longevity pathways converge on autophagy genes to regulate life span in Caenorhabditis elegans. Autophagy, 2008, 4(3), 330-338.

[68] Tatar, M.; Bartke, A.; Antebi, A. The endocrine regulation of aging by insulin-like signals. Science, 2003, 299(5611), 1346-1351.

[69] Kenyon, C. The plasticity of aging: insights from long-lived mutants. Cell, 2005, 120(4), 449-460.

[70] Morley, J.F.; Morimoto, R.I. Regulation of longevity in Caenorhabditis elegans by heat shock factor and molecular chaperones. Mol. Biol. Cell., 2004, 15(2), 657-664.

[71] Morley, J.F.; Brignull, H.R.; Weyers, J.J.; Morimoto, R.I. The threshold for polyglutamine-expansion protein aggregation and cellular toxicity is dynamic and influenced by aging in Caenorhabditis elegans. Proc. Natl. Acad. Sci. USA, 2002, 99(16), 10417-10422.

[72] Greer, E.L.; Dowlatshahi, D.; Banko, M.R.; Villen, J.; Hoang, K.; Blanchard, D.; Gygi, S.P.; Brunet, A. An AMPK-FOXO pathway mediates longevity induced by a novel method of dietary restriction in C. elegans. Curr. Biol., 2007, 17(19), 1646-1656.

[73] Greer, E. L.; Brunet, A. Different dietary restriction regimens extend lifespan by both independent and overlapping genetic pathways in C. elegans. Aging Cell, 2009, 8(2), 113-127. 
[74] Houthoofd, K.; Vanfleteren, J.R. The longevity effect of dietary restriction in Caenorhabditis elegans. Exp. Gerontol., 2006, 41(10), 1026-1031.

[75] Lakowski, B.; Hekimi, S. The genetics of caloric restriction in Caenorhabditis elegans. Proc. Natl. Acad. Sci. USA, 1998, 95(22), 13091-13096.

[76] Panowski, S.H.; Wolff, S.; Aguilaniu, H.; Durieux, J.; Dillin, A. PHA-4/Foxa mediates diet-restriction-induced longevity of C. elegans. Nature, 2007, 447(7144), 550-555.

[77] Bishop, N.A.; Guarente, L. Two neurons mediate diet-restrictioninduced longevity in C. elegans. Nature, 2007, 447(7144), 545-549.

[78] Giannakou, M.E.; Goss, M.; Partridge, L. Role of dFOXO in lifespan extension by dietary restriction in Drosophila melanogaster: not required, but its activity modulates the response. Aging Cell, 2008, 7(2), 187-198.

[79] Lenaerts, I.; Walker, G.A.; Van Hoorebeke, L.; Gems, D.; Vanfleteren J.R. Dietary restriction of Caenorhabditis elegans by axenic culture reflects nutritional requirement for constituents provided by metabolically active microbes. J. Gerontol. A. Biol. Sci. Med. Sci., 2008, 63(3), 242-252.

[80] Kaeberlein, T.L.; Smith, E.D.; Tsuchiya, M.; Welton, K.L.; Thomas, J.H.; Fields, S.; Kennedy, B.K.; Kaeberlein, M. Lifespan extension in Caenorhabditis elegans by complete removal of food. Aging Cell, 2006, 5(6), 487-494.

[81] Lee, G.D.; Wilson, M.A.; Zhu, M.; Wolkow, C.A.; de Cabo, R.; Ingram, D.K.; Zou, S. Dietary deprivation extends lifespan in Caenorhabditis elegans. Aging Cell, 2006, 5(6), 515-524.

[82] Smith, E.D.; Kaeberlein, T.L.; Lydum, B.T.; Sager, J.; Welton, K.L.; Kennedy, B.K.; Kaeberlein, M. Age- and calorie-independent life span extension from dietary restriction by bacterial deprivation in Caenorhabditis elegans. BMC Dev. Biol., 2008, 8, 49.

[83] Hansen, M.; Taubert, S.; Crawford, D.; Libina, N.; Lee, S.J.; Kenyon, C. Lifespan extension by conditions that inhibit translation in Caenorhabditis elegans. Aging Cell, 2007, 6(1), 95-110.

[84] Syntichaki, P.; Troulinaki, K,; Tavernarakis, N. eIF4E function in somatic cells modulates ageing in Caenorhabditis elegans. Nature, 2007, 445(7130), 922-926.

[85] Hahn, J.S.; Hu, Z.; Thiele, D.J.; Iyer, V.R. Genome-wide analysis of the biology of stress responses through heat shock transcription factor. Mol. Cell. Biol., 2004, 24(12), 5249-5256.

[86] Dai, C.; Whitesell, L.; Rogers, A.B.; Lindquist, S. Heat shock factor 1 is a powerful multifaceted modifier of carcinogenesis. Cell, 2007, 130(6), 1005-1018.

[87] Howitz, K.T.; Bitterman, K.J.; Cohen, H.Y.; Lamming, D.W.; Lavu, S.; Wood, J.G.; Zipkin, R.E.; Chung, P.; Kisielewski, A.; Zhang, L.L.; Scherer, B.; Sinclair, D.A. Small molecule activators of sirtuins extend Saccharomyces cerevisiae lifespan. Nature, 2003, 425(6954), 191-196.

[88] Wood, J.G.; Rogina, B.; Lavu, S.; Howitz, K.; Helfand, S.L.; Tatar, M.; Sinclair, D.A. Sirtuin activators mimic caloric restriction and delay ageing in metazoans. Nature, 2004, 430(7000), 686-689.

[89] Baur, J.A.; Pearson, K.J.; Price, N.L.; Jamieson, H.A.; Lerin, C.; Kalra, A.; Prabhu, V.V.; Allard, J.S.; Lopez-Lluch, G.; Lewis, K.; Pistell, P.J.; Poosala, S.; Becker, K.G.; Boss, O.; Gwinn, D.; Wang, M.; Ramaswamy, S.; Fishbein, K.W.; Spencer, R.G.; Lakatta, E.G.; Le Couteur, D.; Shaw, R.J.; Navas, P.; Puigserver, P.; Ingram, D.K.; de Cabo, R.; Sinclair, D.A. Resveratrol improves health and survival of mice on a high-calorie diet. Nature, 2006, 444(7117), 337-342.

[90] Baur, J.A.; Sinclair, D.A. Therapeutic potential of resveratrol: the in vivo evidence. Nat. Rev. Drug Discov., 2006, 5(6), 493-506.

[91] Gruber, J.; Tang, S.Y.; Halliwell, B. Evidence for a trade-off between survival and fitness caused by resveratrol treatment of Caenorhabditis elegans. Ann. N. Y. Acad. Sci., 2007, 1100, 530542 .
[92]

Bass, T.M.; Weinkove, D.; Houthoofd, K.; Gems, D.; Partridge, L. Effects of resveratrol on lifespan in Drosophila melanogaster and Caenorhabditis elegans. Mech. Ageing Dev., 2007, 128(10), 546552.

[93] Pearson, K.J.; Baur, J.A.; Lewis, K.N.; Peshkin, L.; Price, N.L.; Labinskyy, N.; Swindell, W.R.; Kamara, D.; Minor, R.K.; Perez, E.; Jamieson, H.A.; Zhang, Y.; Dunn, S.R.; Sharma, K.; Pleshko, N.; Woollett, L.A.; Csiszar, A.; Ikeno, Y.; Le Couteur, D.; Elliott, P.J.; Becker, K.G.; Navas, P.; Ingram, D.K.; Wolf, N.S.; Ungvari, Z.; Sinclair, D.A.; de Cabo, R. Resveratrol delays age-related deterioration and mimics transcriptional aspects of dietary restriction without extending life span. Cell Metab., 2008, 8(2), 157-168.

[94] Viswanathan, M.; Kim, S.K.; Berdichevsky, A.; Guarente, L. A role for SIR-2.1 regulation of ER stress response genes in determining C. elegans life span. Dev. Cell, 2005, 9(5), 605-615.

[95] Brunet, A.; Sweeney, L.B.; Sturgill, J.F.; Chua, K.F.; Greer, P.L.; Lin, Y.; Tran, H.; Ross, S.E.; Mostoslavsky, R.; Cohen, H.Y.; Hu, L.S.; Cheng, H.L.; Jedrychowski, M.P.; Gygi, S.P.; Sinclair, D.A.; Alt, F.W.; Greenberg, M.E. Stress-dependent regulation of FOXO transcription factors by the SIRT1 deacetylase. Science, 2004 303(5666), 2011-2015.

[96] Picard, F.; Kurtev, M.; Chung, N.; Topark-Ngarm, A.; Senawong, T.; Machado De Oliveira, R.; Leid, M.; McBurney, M.W.; Guarente, L. Sirt1 promotes fat mobilization in white adipocytes by repressing PPAR-gamma. Nature, 2004, 429(6993), 771-776.

[97] Nemoto, S.; Fergusson, M.M.; Finkel, T. SIRT1 functionally interacts with the metabolic regulator and transcriptional coactivator PGC-1\{alpha\}. J. Biol. Chem., 2005, 280(16), 16456-16460.

[98] Tissenbaum, H.A.; Guarente, L. Increased dosage of a sir-2 gene extends lifespan in Caenorhabditis elegans. Nature, 2001, 410(6825), 227-230.

[99] Banks, A.S.; Kon, N.; Knight, C.; Matsumoto, M.; GutierrezJuarez, R.; Rossetti, L.; Gu, W.; Accili, D. SirT1 gain of function increases energy efficiency and prevents diabetes in mice. Cell $\mathrm{Me}$ tab., 2008, 8(4), 333-341.

[100] Pfluger, P.T.; Herranz, D.; Velasco-Miguel, S.; Serrano, M.; Tschop, M.H. Sirt1 protects against high-fat diet-induced metabolic damage. Proc. Natl. Acad. Sci. USA, 2008, 105(28), 9793-9798.

[101] Lin, S.J.; Defossez, P.A.; Guarente, L. Requirement of NAD and SIR2 for life-span extension by calorie restriction in Saccharomyces cerevisiae. Science, 2000, 289(5487), 2126-2128.

[102] Wang, Y.; Tissenbaum, H.A. Overlapping and distinct functions for a Caenorhabditis elegans SIR2 and DAF-16/FOXO. Mech. Ageing Dev., 2006, 127(1), 48-56.

[103] Boily, G.; Seifert, E.L.; Bevilacqua, L.; He, X.H.; Sabourin, G.; Estey, C.; Moffat, C.; Crawford, S.; Saliba, S.; Jardine, K.; Xuan, J.; Evans, M.; Harper, M.E.; McBurney, M.W. SirT1 regulates energy metabolism and response to caloric restriction in mice. PLoS ONE, 2008, 3(3), e1759.

[104] Parker, J.A.; Arango, M.; Abderrahmane, S.; Lambert, E.; Tourette, C.; Catoire, H.; Neri, C. Resveratrol rescues mutant polyglutamine cytotoxicity in nematode and mammalian neurons. Nat. Genet., 2005, 37(4), 349-350.

[105] Kim, D.; Nguyen, M.D.; Dobbin, M.M.; Fischer, A.; Sananbenesi, F.; Rodgers, J.T.; Delalle, I.; Baur, J.A.; Sui, G.; Armour, S.M.; Puigserver, P.; Sinclair, D.A.; Tsai, L.H. SIRT1 deacetylase protects against neurodegeneration in models for Alzheimer's disease and amyotrophic lateral sclerosis. EMBO J., 2007, 26(13), 31693179.

[106] Putics, Á.; Végh, E.M.; Csermely, P.; Sőti, C. Resveratrol induces the heat-shock response and protects human cells from severe heat stress. Antioxid. Redox Signal., 2008, 10(1), 65-75.

[107] Westerheide, S.D.; Anckar, J.; Stevens, S.M., Jr.; Sistonen, L.; Morimoto, R.I. Stress-inducible regulation of heat shock factor 1 by the deacetylase SIRT1. Science, 2009, 323(5917), 1063-1066. 